MANUEL DARÍO PALACIO MUÑOZ

Universidad de los Andes - Colombia

Ruhr Universität Bochum - Deutschland

md.palacio10@unad.edu.co

\title{
Mitología y Revelación: Las interpretaciones de Schelling en "La Querella Por El Politeísmo" entre Marquard y Taubes
}

\author{
Mythology and Revelation: The interpretations of Shelling \\ on «The question about Polytheism» between Marquard \\ and Taubes
}

RESUMEN: El siguiente texto presenta la disputa en torno al politeísmo que tuvo lugar entre Taubes y Marquard y a las interpretaciones que ambos ofrecen de la filosofía de Schelling. Mientras que Marquard sostiene que la filosofía de la mitología no puede superar la esfera de la heteronomía, ni siguiera con la filosofía de la revelación, Taubes asume que la filosofía de la revelación expresa el reino de la autonomía y en consecuencia es el motivo definitivo de la filosofía de la historia. Tras presentar las partes encontradas, se hace un balance de la discusión.

PALABRAS CLAVE: JACOB TAUBES; ODO MARQUARD; POLITEISMO; REVELACIÓN; MITOLOGÍA; SHCELLING
ABSTRACT: The following text presents the discussion between Marquard and Taubes about de "question of the polytheism", and their corresponding interpretations of Schelling's philosophy as well. While Marquard aims that philosophy of mythology does not allow to go further to heteronomy, nor after its transformation into philosophy of revelation, Taubes understands the philosophy of revelation as expression of the autonomy's reign, and consequently, it is the ultimate goal of the philosophy of history. After the discussion, the author makes a balance of the discussion.

KEYWORDS: JACOB TAUBES; ODO MARQUARD; POLYTHEISM; REVELATION; MYTHOLOGY; SCHELLING 


\section{INTRODUCCIÓN}

$\mathrm{O}$ do Marquard (1929-2015) y Jacob Taubes (1923-1987) participaron activamente como miembros del grupo Poetik und Hermeneutik, que desarrolló una actividad investigativa y de producción académica en el marco de las ciencias del espíritu desde 1963 hasta 1994 en 17 sesiones. La participación tanto de Odo Marquard (filósofo) y Jacob Taubes (Teólogo) los vinculó en los diversos temas que se trataron en cada una de las sesiones del grupo, además de conectarlos en la esfera académica de la Alemania de la postguerra; de este modo, participaron más de una vez en volúmenes recopilatorios en torno a diferentes temas, como los tres volúmenes editados por Taubes acerca de $R e$ ligionstheorie und politische Theologie, y sin embargo, la propuesta de ambos autores se marca en extremos opuestos de la misma discusión. Así, mientras que Marquard reconoce en Taubes a un continuador del gnosticismo acósmico y anómico en la comprensión de la filosofía de la historia a partir de su trabajo sobre la revelación como elemento principal de la historia, Taubes considera que la alabanza al politeísmo llevada a cabo por Marquard no solo desprestigia la pregunta por la historia y la divinidad, sino que es fundamentalmente antiilustrada. Curiosamente, en el centro de la argumentación de ambos autores aparece la figura de Schelling, en particular, a través de su tematización de las relaciones y transmutaciones entre mitología y revelación. Dado que ambos autores apelan al pensamiento de Schelling para argumentar sus posturas, incluso a partir de los mismos pasajes, mi propósito en este texto es doble: en un primer momento, presento lo que he denominado como "querella por el politeísmo", señalando las tensiones que se erigen entre el pensamiento de Marquard y Taubes con la mediación de la figura de Schelling a partir de los dos debates que gestaron tal querella. En un segundo, que es el conclusivo, presento mi postura personal al debate, intentando inclinar la balanza a la tesis defendida por Marquard ante tal querella, quien, una vez más apelando al rol de conceptualización de la filosofía de la mitología de Schelling, abre un nuevo camino para entender la pregunta de la filosofía de la historia en el marco del idealismo.

\section{La Querella por el Politeísmo: Primera apelación a Schelling}

El contexto general de las desavenencias filosóficas entre Taubes y Marquard ha sido descrito como la lucha por el significado de la modernidad, en palabras de Ritz (Ritz, 2015), que a su vez describe el problema como una confrontación de perspectivas ante la filosofía de la historia y su vinculación con la teología de la historia. De este modo, el «teorema de la secularización» es la piedra angular de este debate, que incluye a otros filósofos como Löwith, Blumenberg, Lübbe, y un largo etcétera; y es sobre el debate en torno a la legitimidad de tal teorema, que la cuestión por el politeísmo adquiere un nuevo 
matiz, ya que la teología de la historia, así como la filosofía de la historia, habían partido de un supuesto monista, o lo que es lo mismo en este caso, monoteísta. Este presupuesto se consolida en la tesis de la continuidad, es decir, en aquella que establece que la filosofía de la historia es una secularización de la teología de la historia. Esta es la consideración de Taubes cuando reconstruye la discusión:

Löwith ha demostrado que la filosofía de la historia está conectada con la teología de la historia, lo que tanto Löwith como Marquard encuentran como negativo. Yo en cambio sostengo que este es un nexo positivo, el que se establece con la filosofía de la historia. (Taubes, 1987: 316). ${ }^{1^{*}}$

Taubes pertenece a quienes defienden la tesis de una legítima continuidad entre la teología de la historia y la filosofía de la historia. Por su parte, Marquard toma distancia de esta interpretación y trata de marcar un punto más mesurado, expresando que más que de la continuidad, se trata de una cuestión por la legitimidad o ilegitimidad de este tránsito; de esto modo, Marquard reconstruye la discusión poniendo a Taubes como el representante de la postura que legitima el tránsito de la secularización, de la teología a la filosofía de la historia:

Para Löwith en la filosofía de la historia se prolonga de modo legítimo la ilegitimidad de la doctrina bíblica de la salvación; para Taubes, aquella prolonga de modo legítimo la legitimidad de la doctrina bíblica de la salvación. Para Löwith la teología de la historia era ya mala, para Taubes, la filosofía de la historia es tanto más buena y aún sigue siéndolo. (Marquard, 2007: 21-22)

La discusión en torno a la secularización constituye el telón de fondo en el que tiene lugar lo que denominamos como "querella por el politeísmo", pues se trata de un giro adicional respecto a la pregunta por la validez del teorema de la secularización. Si el teorema de la secularización se pregunta por la legitimidad y posibilidad de la continuación que la filosofía de la historia moderna adquiere respecto a la teología de la historia anterior, la querella por el politeísmo pregunta por ciertos motivos teológicos, en particular en los que refieren a Dios como causa y fin, esto es, como creador y redentor del mundo; a la vez que matiza estas consideraciones en torno a la lectura de la filosofía de la historia moderna. Así, en sentido estricto, no hubo una "querella por el politeísmo" como una disputa

[1] * Por efectos de homogeneidad idiomática en el texto, he decidido traducir todas las citas que no estén en español. De este modo, en una nota al pie se indica el texto original y en el texto se encuentra la traducción que he realizado. Los textos que poseen traducción al español los he citado directamente en español, sin poner la cita en el idioma original.

[2] El original en alemán dice: „Löwith hat den Nachweis führen wollen, dass die Geschichtsphilosophie mit der Geschichtstheologie zusammenhängt, was von Löwith bis Marquard als negativer Einwand gilt. Ich selbst halte gerade diesen Nexus für das Positivste an der Geschichtsphilosophie.“ (Taubes, 1987: 316) 
filosófica abierta a contribuciones de los diferentes autores y lo que estamos entendiendo aquí por querella por el politeísmo se enmarca específicamente en el ámbito del teorema de la secularización y por tanto, quedan de lado otras consideraciones sobre el politeísmo en el mundo contemporáneo. ${ }^{3}$

Los textos fundamentales de esta disputa, tal y como la formula Macho (2001), son Lob des Polytheismus de Odo Marquard, publicado inicialmente en el volumen Philosophie und Mythos aparecido en 1979, y el texto de Taubes titulado Zur Konjunktur des Polytheismus, publicado en el volumen Mythos und die Moderne aparecido en el año 1983. No obstante, es posible rastrear esta disputa poco más de una década hacia atrás, en la sesión cuarta del grupo Poetik und Hermeneutik cuyas memorias fueron publicadas en el volumen Terror und Spiel: Probleme der Mythenrezeption; tras este rastreo, queda patente que la confrontación entre Taubes y Marquard surge precisamente de la contraposición entre las lecturas de Schelling que ambos autores ofrecen.

\section{MARQUARD: LA FILOSOFÍA DE LA MITOLOGÍA DE SCHELLING COMO HETERONOMÍA}

El motivo por el que se trae a colación a Schelling es el intento de definir el rol de la filosofía de la mitología en el corpus de su obra. Este es un trabajo que Marquard aborda en su colaboración presentada en la cuarta sesión del grupo Poetik und Hermeneutik, y que titula Zur Funktion der Mythologiephilosophie bei Schelling. Marquard parte de la pregunta acerca de por qué Schelling se ocupa de una filosofía de la mitología, y para resolverla reconstruye las contribuciones de Schelling al tema, empezando por la diferencia establecida entre Verdad (Wahrheit) y Fábula (Fabel), que aparece en la Magisterdisertation del año 1792; prosigue rastreando las ideas de una nueva mitología, que aparecen ya en el más antiguo programa de un sistema del idealismo alemán, y que se repiten en Die neue Mythologie als Mittelglied der Rückkehr der Wissenschaft zur Poesie (Schelling III, p. 629) y en los textos relativos a Homero, al arte, en los aforismos de ciencia natural, hasta llegar a las edades del mundo; y finaliza su rastreo con los textos posteriores a 1815, cuyo culmen son las lecciones que componen la Philosophie der Mythologie que el Schelling tardío ofreció entre 1837 y 1842. Con este rastreo, demuestra Marquard que el tema de una filosofía de la mitología es transversal a la obra de Schelling, y en consecuencia, puede tomarse como un elemento significativo de su filosofía.

Y sin embargo, pese a que la preocupación por la filosofía de la mitología atraviesa los sistemas de Schelling, constituye una dificultad en su misma fi-

[3] La conceptualización de esta „querella por el politeísmo" está tomada de la formulación que de la misma ofrece Thomas Macho en términos de "die Kontroverse, die Taubes mit Odo Marquard um dessen "Lob des Polytheismus" austrug". (Macho, 2001: 542). 
losofía. Puede caracterizarse a Schelling como un filósofo que se esfuerza por afirmar y defender la autonomía humana, caracterización compartida por el mismo Marquard, y no obstante, la mitología solo puede ofrecer una perspectiva autónoma en términos de una "crítica de la mitología" como crítica de las ilusiones que pretenden hacer valer un mito en lugar de la experiencia. De este modo, prosigue Marquard, el único camino para que la mitología se erija como componente autónomo de la historia de la conciencia es, precisamente, como crítica del mito. Pero la propuesta de Schelling no es tal, ya que "la filosofía de la mitología no es ninguna crítica de la mitología" (Marquard, 1971: 259), ${ }^{4}$ de modo que la filosofía de la mitología se transforma en un elemento antinómico, pues "la mitología es historia heterónoma" (Marquard, 1971: 259). ${ }^{5}$ En consecuencia, Marquard encuentra una paradoja en su propia interpretación de Schelling, ya que si "el hombre, él solamente, hace su mundo; el hombre, él solamente, hace la historia, esto significa, que cada historia es historia autónoma" (Marquard, 1971: 259), ${ }^{6}$ entonces la mitología habría de contribuir a tal autonomía, pero ocurre precisamente lo contrario. ¿Cómo es esto?

Marquard insiste en que los esfuerzos de Schelling, por erigir la autonomía humana como elemento de la historia, constituyen una forma de resolver los problemas que la teodicea no había podido resolver. De este modo, la apelación a la autonomía humana constituye un descargo de Dios, deviniendo una tarea humana el hacerse cargo del mal, en sus forma física, moral y metafísica; Sin embargo, tal tarea resulta excesiva para el ser y precisa de unos auxiliares sucedáneos que le ayuden a completar tal empresa. Por un lado, se reivindica, por debajo del ser humano, a la naturaleza; y por encima del ser humano, a Dios. Naturaleza y Dios aparecen en escena para ayudar en la tarea humana de hacerse responsables por el "destino del mundo". La naturaleza le provee de una cierta forma sensible de la idea. Dios aparece más bien como una ambivalencia, pues no es el creador, pero de alguna manera aparece como fundamento. Por eso Marquard insiste en que esta formulación de la tesis de la autonomía invoca a Dios al tiempo que lo hace irreal (Marquard, 2007: 70); ya que hace de Dios un ser necesario pero no resulta ser más que un postulado. Estas consideraciones las lee directamente Marquard en Schelling: kritik“.

[4] El original en alemán dice: "Schellings Mythologiephilosophie ist keine Mythologie-

[5] El original en alemán dice: "Mythologie ist heteronome Geschichte"

[6] El original en alemán dice: „Also der Mensch - er allein — macht seine Welt; der Mensch - er allein - macht die Geschichte; das aber bedeutet: jede Geschichte ist autonome Geschichte“ 
Schelling retoma allí el problema de la teodicea y expone su específica forma de solución... Esto es así en el escrito sobre la Libertad de Schelling: Dios mismo (Existenz) se tiene con el fundamento (Grund) en Dios, con la naturaleza en Dios tan pesada, que tal peso adquirido debe abrir las posibilidades del mal... Así, la respuesta de la autonomía es: Dios "ha" dejado de hacer la creación, pues no es Dios quien ha hecho el mundo, sino el hombre, por lo menos como mundo cultural... De este modo, el autonomismo es... un ateísmo para la mayor gloria de Dios, mediante la conclusión que la bondad divina no existe, se obtiene el resultado: La teodicea ha sido un éxito, pero Dios ha muerto. (Marquard, 1995: 55-59) ${ }^{7}$

Así, la consecuencia de la afirmación de la autonomía resuelve la pregunta de la teodicea mediante su eliminación, ya que la creación del mundo y la historia son tareas humanas, y en consecuencia, el mal es un asunto vinculado al hacer del hombre más que a la permisividad divina. Dios queda exonerado, pero resulta innecesario. El camino recorrido por Schelling, para proponer la autonomía humana como respuesta a la pregunta por la teodicea, procede entonces en dos vías: la primera es la tendencia a descargar a Dios del mal (die Tendenz zur Entlastung Gottes); y la segunda es la tendencia a la desmalignización del mal (Die Tendenz zur Entübelung der Übel) (Marquard, 1981: 206-207). Ambas estrategias están orientadas a la transformación de la teodicea en filosofía de la historia, en tanto que vinculan el desarrollo de la autonomía humana con la historia; y de este modo, la respuesta a la pregunta por la teodicea solo tiene lugar en el tiempo, en tanto que solo en la historia es plausible el advenimiento del reino de la autonomía sobre el mundo. Y sin embargo, esta tarea resulta conflictiva en sí misma porque la exoneración de Dios exige que el hombre tome su lugar, que ostente los atributos de creador infinito y omnipotente, pero la desmalignización del mal implica la positivización de la finitud humana y los límites de su intelección (Marquard, 1981: 208). Así que esta contraposición, en la que el mal vuelve a presentarse como un problema, marca el tránsito del joven Schelling al Schelling tardío (Marquard, 1981: 210). Revisemos este punto más detalladamente.

Schelling invierte la estrategia de la desmalignización (Entübelung) del mal, llevada a cabo por la teodicea, a una de la remalignización (Renegativierung)

[7] El original en alemán dice: „...weil dort Schelling das Theodizeeproblem aufnimmt und seinen spezifischen Lösungsansatz exponiert... Und in Schellings Freiheitsschrift ist es so: Gott selbst („Existenz“) hat es mit dem „Grund“ in Gott, der Natur in Gott so schwer, dass durch dieses Schwerhaben Gott die Möglichkeit des Bösen eröffnen muss... Die autonomistische Antwort ist: Gott ,hat' das Schaffen bleibenlassen, denn nicht Gott hat die Welt geschaffen, sondern der Mensch, zumindest als Kulturwelt... Der Autonomismus ist ein ,Atheismus ad maiorem Die gloriam' durch den Schluss von der Güte Gottes auf seine Nichtexistenz mit dem Resultat: Theodizee gelungen, Gott tot.“ 
del mal: el mal físico adquiere valor como enfermedad, tema al que Schelling se dedica en cierta medida (con textos como Theorie der Krankheit als Disharmonie en 1799; Zur Theorie der Krankheit als Regression en 1810, entre otros); y el mal moral adquiere valor en tanto que es expresión de la libertad humana, tal y como queda descrito en sus escritos sobre la libertad humana de 1809 (Philosophische Untersuchungen über das Wesen der menschlichen Freiheit). La conclusión que obtiene Marquard de este análisis es que: "el problema del mal permanece también y recién para el Schelling tardío en el pensum de una teodicea, en la forma de una filosofía de la historia de la culminación de la historia..." (Marquard, 1981: 211). ${ }^{8}$ De este modo, la autonomía que exonera al Dios de la teodicea y que debía hacerse cargo del peso por la existencia del mal, no puede soportar la desmalignización del mal y lo repositiviza con la aspiración de que el desarrollo de la historia resuelva el problema por una carga que no pudo reasignarse en el tránsito de la teodicea a la filosofía de la historia. El corolario que se sigue de esta consideración es que la historia, llevada a cabo por la autonomía, precisa del reconocimiento del mal concomitante a su desarrollo, de modo que la autonomía no logra aliviar el mal, sino que lo positiviza como consecuencia de su desarrollo, con lo que el mal es un lastre necesario de la libertad, pero del cual la autonomía no logra hacerse cargo, a menos no hasta la consumación de la historia.

Estas consideraciones de la consumación de la historia como forma de aliviar el problema del mal le revelan a Marquard la antitética de la heteronomía como elemento en la filosofía de la historia que no logra compaginar con el desarrollo de la autonomía humana. De este modo, Marquard opina que la consigna de que "el hombre es quien hace la historia" es puramente una ilusión, pues la autonomía se revela a su vez dependencia como de los demás, ${ }^{9}$ en tanto que la consumación de la historia es siempre un acto que ocurre necesariamente a través de los demás. Para ilustrarlo, Marquard presenta el caso del Estado y la revolución como formas consumadas de la historia:

[8] El original en alemán dice: "das Problem des Bösen bleibt auch und gerade beim späte Schelling das Pensum einer Theodizee in Gestalt einer Geschichtsphilosophie der Vollendungsgeschichte"

[9] Marquard lo indica expresamente: „Daß der Mensch die Geschichte macht, daß er sie selber in seiner Hand hat: das ist - einstweilen - eine Illusion. Zwar könnte es zu gutem Zwecke die Aufgabe der Philosophie sein, derlei Illusionen aufrechtzuerhalten; denn das Wahre ist das Halbe: die andere Hälfte besteht aus Anstrengungen, durch das Wahre sich nicht umbringen zu lassen. Allein: wo die Philosophie es ablehnt, Illusionen zu verteidigen, wird sie zugeben müssen, daß in der Geschichte verwirklichte Autonomie einstweilen stets abgetretene Autonomie ist. Autonom: das ist - einstweilen - jedermann immer nur durch Anderes, von dem er dann abhängig wird.“ (1971, pág. 260) 
El estado y la revolución. Ambos son únicamente posibles, en tanto que el individuo pase de la libertad de acción a la acción misma, que no es la misma libertad. Quizás por esto haya para esta historia, justo aquí donde ella se entiende como autónoma, el mito de esa historia: la mítica cualidad de las ciencias exactas; el mito del leviatán, el mito de la huelga general. Con lo que se indica: La historia hecha por los hombres es, por el momento, siempre al mismo tiempo la historia no hecha por los hombres. (Marquard, 1971: 260) ${ }^{10}$

Con ello ha vuelto Marquard a la mitología, esta vez no para designar el proyecto de una nueva mitología, sino para mostrar que el desarrollo de una filosofía de la mitología revela que la historia no es, principalmente, el terreno de la autonomía humana, (Marquard, 1971: 261) Marquard asegura que Schelling está convencido de esta tesis, debido a la ausencia de caminos concretos que resuelvan la filosofía de la historia en Schelling: carece de una teoría del Estado como la formulada por Hegel, de una concreta teoría de la revolución, como la formulada por Marx; y esta ausencia expresa más que una falencia, pues indica que Schelling mismo no logró consolidar un camino para la consumación de la historia como desarrollo de la autonomía humana.

Un intento alternativo es diagnosticado por Marquard en la inclinación de Schelling al arte, que se revela a sí mismo como el exilio de la autonomía (das Exil der Autonomie ist die Kunst) (Marquard, 1971: 261), ya que si el hombre no logra su autonomía en la historia, puede intentarlo de manera extrahistórica; de modo que el arte se erige como escenario adecuado para el desarrollo de la autonomía, porque en el arte se abre un espacio de libertad sin precedentes en el espíritu humano. Y sin embargo, tal tentativa se ve envuelta en las mismas dificultades que la filosofía de la historia, pues el arte apela de nuevo a la alternativa de la Naturaleza y Dios como realidades redentoras (rettende Wirklichkeiten) "las realidades convidadas de Naturaleza y Dios toman la última posible autonomía del hombre: la estética”. (Marquard, 1971: 262). ${ }^{11}$ Ahora bien, ya que Schelling define a la mitología como el material del arte (Schelling V, p. 388-457), definición que aparece en las tempranas lecciones sobre filosofía de la mitología, resulta que la mitología se encuentra en la estructura neural del sistema de la identidad, ya que el arte no presenta la naturaleza ni a Dios, sino

[10] El original en alemán dice: Und Staat und Revolution: beides ist nur möglich, indem der Einzelne seine Handlungsfreiheit abtritt an Aktionen, die nicht er selber ist. Vielleicht gerade darum gibt es für diese Geschichte - und zwar just dort, wo sie sich als autonome versteht - die Mythen dieser Geschichte: die mythische Qualität des exakten Wissenschaftlers; den Mythos des Leviathan; den Mythos des Generalstreiks. Gerade das zeigt an: die vom Menschen gemachte Geschichte ist - einstweilen - immer auch zugleich die nicht vom Menschen gemachte Geschichte."

[11] El original en alemán dice: "Die herbeigerufenen Wirklichkeiten Natur und Gott nehmen dem Menschen die letzte ihm mögliche Autonomie: die ästhetische." 
a la mitología, en tanto que es "la realidad misma a la que se apela en lugar de esas otras realidades" (Marquard, 1971: 262). ${ }^{12}$ Pero del mismo modo que la apelación a la Naturaleza y a Dios sustraen la autonomía humana, así lo hace la mitología, pues desplaza las realidades redentoras que descargaban al hombre del problema del mal ante la postulación de una autonomía total.

En consecuencia, advierte Marquard, Schelling utiliza la mitología como estrategia para lograr una custodia indirecta de la autonomía, a través de la mediación de la mitología. Schelling reconoce el valor estético de la mitología, incluso en los términos de una filosofía de la identidad, en la que en el arte Dios y Naturaleza alcanzan su comunión; y sin embargo, reconoce que esta apelación de sucedáneos en el desarrollo del espíritu son obstáculos para la realización de la historia como fruto del despliegue de la autonomía. La mitología adquiere un valor metafísico como expresión de la identidad, pero conviene retirarla de la historia para custodiar la autonomía; o dicho en breve: Schelling le dice sí a la mitología (Bejahung), al tiempo que ésta le estorba (Durchkreuzen): "La mitología es entronizada, pero - y según Schelling de ello se ocupa el poder desmitologizador del cristianismo - no puede tener ninguna vitalidad actual" (Marquard, 1971: 262). ${ }^{13}$

Por esta razón, para Schelling, la última nueva mitología fue precisamente el cristianismo, y en consecuencia, cualquier intento de mitología debe proyectarse históricamente a los extremos mismos de la historia: a un pasado remoto, o a un futuro en que ocurra la consumación de la historia. La mitología se vuelve entonces un sucedáneo de descarga para las cargas pesadas: la creación y la redención del mundo, por ello conviene desplazarlos a los extremos de la historia; en la mitad, es decir, en la historia, no conviene una mitología sino propiamente la historia:

La filosofía de la mitología de Schelling es heteronomismo directo, pero es indicetamente autonomismo. Ella alaba los mitos (loben), pero lo hace para despedirlos (wegloben) en un futuro lejano o en un pasado lejano. De este modo, el presente se hace libre, no como historia, sino como arte; y es libre, cuando menos, de aceptar mitos o de no hacerlo. (Marquard, 1971: 263). ${ }^{14}$

[12] El original en alemán dice: „die Kunst präsentiert also nicht Natur und nicht Gott, sondern eben das, was als Wircklichkeit statt jener Wircklichkeiten von Schelling gerufen wurde: die Mythologie“

[13] La cita en alemán dice: „die Mythologie wird inthronisiert, aber sie darf - und dafür sorgt nach Schelling die entmythologisierende Kraft des Christentums - keine gegenwärtige Lebendigkeit haben."

[14] El original en alemán dice: „Schellings Mythologiephilosophie: das ist direkter Heteronomismus; aber es ist indirekter Autonomismus; sie lobt die Mythen; aber sie lobt sie weg: ¡n fernste Zukunft und in fernste Vergangenheit. Die Gegenwart macht sie dadurch frei, 


\section{TAubes: LA Filosofía DE LA REVElación COMO RESPUESTA A LOS PROBLEMAS DE LA FILOSOFÍA DE LA MITOLOGÍA}

Los encuentros del grupo Poetik und Hermeneutik no solo permitían que los ponentes presentaran sus intervenciones en torno al tema en cuestión, sino que abrían el espacio para una discusión académica sobre las contribuciones leídas. Es en el marco de esta discusión que Taubes responde, por primera vez, a la interpretación que Marquard ofrece de Schelling, prefigurando sus argumentos fundamentales para la defensa de una filosofía de la revelación como solución a los problemas que genera una filosofía de la mitología. Así, en la sexta discusión de la cuarta reunión del grupo dirigida por Peter Szondi, se debate en torno a las tesis de Marquard y su interpretación que hace del pensamiento de Schelling. Nos interesa para nuestro cometido, específicamente, la intervención de Taubes y la respuesta que le ofrece Marquard.

Tras una primera intervención de Peter Szondi que encuentra poco canónica la lectura ofrecida por Marquard de la filosofía de la mitología de Schelling, Taubes considera que la propuesta de Marquard se queda a medio camino en la propuesta de Schelling, ya que desarrolla los elementos heterónomos de la filosofía de la mitología, pero no da el paso siguiente a la filosofía de la revelación. De este modo, señala Taubes que la filosofía de la revelación y la filosofía de la mitología se pertenecen mutuamente, por lo que conviene realizar dicho tránsito. Taubes insiste en la lectura usual: "Filosofía significa para Schelling: Autonomía" (1971: 642), y esta lectura resulta transversal del joven Schelling hasta el tardío. Taubes asume que las distintas etapas del pensamiento de Schelling van transformando tal concepción de la autonomía; así, ofrece una reconstrucción del rol del arte en las etapas de la filosofía de Schelling, desde su acercamiento a los postulados de Schiller, hasta las consideraciones tardías en que la reconciliación estética desaparece ante la presencia de la filosofía de la revelación: "La revelación satisface, para el Schelling tardío, las exigencias con las que el arte se había enfrentado en sus trabajos de juventud" (1971: 642). ${ }^{15}$ Y ya que Schelling entiende revelación en sentido cristiano, como revelación encarnada, es en este momento que la autonomía vuelve a entrar en la historia mediante la figura del Dios como Señor (Gott als Herr des Seins).

La propuesta de Taubes adquiere queda téticamente formulada: la filosofía de la mitología precisa de ser completada con la filosofía de la revelación, de lo contrario, es imposible un tránsito a la esfera de la autonomía, que solo existe como fruto de la revelación. Pues, opina Taubes, la mitología y la revelación son

nicht zwar die Geschichte, wohl aber die Kunst: diese wird mindestens frei, Mythen zu rezipieren - oder auch nicht.“

[15] El original en alemán dice: „Erst Offenbarung erfüllt für den späten Schelling den Anspruch, mit dem einst Kunst in seinem Jugendwerk auftrat“ 
entendidas por Schelling como potencias realmente históricas. Ello conduce a una caracterización de la historia en tres estadios, y que conviene a la filosofía de Schelling: mitología, revelación y filosofía. Así, la revelación no es el último estado en la odisea del espíritu, pero es el estado que sigue a la mitología, donde se superan las dificultades inherentes a la heteronomía del mito, ya que el mito es, en palabras de Schelling, la edad media del espíritu ${ }^{16}$. Por ello, afirma Taubes, para el Schelling tardío "lo que vale no es una exégesis mítica de la mitología, ni una exégesis teológica de la revelación, sino una filosofía de la mitología y de la revelación" (1971: 643). ${ }^{17}$ Lo definitivo es, entonces, que la filosofía no puede ahorrarse el tránsito por la revelación.

Estas ideas fueron sostenidas por Taubes desde sus comienzos académicos. En el texto Logos und Telos que fue publicado en 1947, el joven Taubes ya afirmaba análogas ideas: "La revelación es el sujeto de la historia, la historia es el predicado de la revelación" (2017, pág. 22), ${ }^{18}$ y prosigue caracterizando a la revelación como el fuego que alumbra entre Dios y el mundo, favoreciendo la revelación de Dios a los hombres y de los hombres al mismo Dios. Esta idea la rastrea directamente en Schelling, asumiendo que podría calificarse la revelación como aquella llama en que juntamente arden naturaleza e historia (Schelling III, 628), y por consiguiente, la revelación sería condición sine qua non de la consecución de la autonomía en el ámbito de una historia de la conciencia. Así que, tras estas acotaciones, Taubes formula su pregunta: "Quisiera preguntarle a Marquard, si para él resulta convincente esta interpretación del Schelling tardío, que amplía su estrategia hasta a la filosofía de la revelación" (1971: 643). ${ }^{19}$

A Marquard apenas si le resulta plausible la propuesta de Taubes. No descarta que convenga leer la filosofía de la mitología a la luz de la filosofía de la revelación, ya que el mismo Schelling subsume la primera en la segunda, pero Marquard le reprocha a Taubes que haya dejado de lado su dilema por tratar de buscarle una solución demasiado rápida. Marquard pone dos reservas que le impiden aceptar inmediatamente la propuesta de Taubes. La primera consiste en que si el futuro es definido a través de la revelación, y así lo establece Schelling

[16] Así lo indica Taubes sin referir la cita: "Er sprach vom Mythos als Mittelalter des Geistes"

[17] El original en alemán dice: „Festzuhalten gilt, daß der späte Schelling weder eine mythische Exegese der Mythologie noch eine theologische Exegese der Offenbarung, sondern eine Philosophie der Mythologie und Offenbarung."

[18] El original en alemán dice: „Die Offenbarung ist das Subjekt der Geschichte, die Geschichte ist das Prädikat der Offenbarung.“

[19] El original en alemán dice: „Ich möchte Marquard fragen, ob ihm diese Interpretation des späten Schelling,

die seine Strategien auch auf die Offenbarungsphilosophie ausdehnt, noch einleuchtet.“ 
mediante el reino del espíritu y la filosofía de la religión, entonces la filosofía de la revelación se hipertrofia y trata de resolver los problemas de la mitología, a la vez que los del arte y de la historia misma. Esto es, la filosofía de la revelación sería la única filosofía. La segunda objeción radica en que el conflicto entre mito y autonomía no queda claramente resuelto en la lectura de Taubes, quien pasa por alto el matiz individual de la autonomía en el marco de una filosofía de la revelación. De este modo, Marquard queda poco satisfecho con esta opción:

He leído e interpretado la filosofía tardía de Schelling de tal modo, que me he bloqueado frente a ella: en últimas, porque yo no comprendo la conformidad entre revelación y autonomía (1971: 643). ${ }^{20}$

De este modo ha quedado plasmada la confrontación entre Marquard y Taubes en los términos de los intereses filosóficos de cada autor, y en consecuencia, esta se radicaliza con el desarrollo de las propuestas filosóficas de ambos. Por un lado, Marquard interpreta la postulación de la autonomía como intento de respuesta al problema del mal, pregunta heredada de la teodicea y resuelta en una filosofía de la libertad; con ello, vincula el proyecto de la filosofía de la mitología de Schelling al intento de resolver las dificultades que la teodicea y la filosofía de la historia tienen al encarar la pregunta con el mal. La conclusión de Marquard es que una filosofía de la mitología es una salida modesta al problema, en tanto que defiende indirectamente la autonomía en la historia, mediante el desplazamiento de la heteronomía del mito al pasado y al futuro más remotos. Por otro lado, Taubes considera que solo en la revelación es posible comprender la autonomía como desarrollo de la conciencia en la historia, y en consecuencia, la libertad solo surge en el ámbito de una revelación, que sirve de liberación, precisamente, de las limitaciones impuestas heterónomamente por la mitología. Tras esta discusión llevada a cabo en 1968, surgirá una nueva discusión entre ambos pensadores, ya no presencialmente, sino con la publicación de dos textos: la alabanza del politeísmo de Marquard, y sobre el auge el politeísmo de Taubes. El desarrollo de este segundo capítulo del debate nos ocupará en el siguiente apartado.

\section{Mitología y Revelación en CUestión: LA SEGUNDA APELACIÓN A SCHELLING}

Las obras de Odo Marquard y Jacob Taubes recorren diversas rutas en la década de los 70's y apuntan a diferentes horizontes de trabajo que van distanciando a los dos autores a partir de la escisión ya marcada en el año de 1968. Marquard se consagra como un filósofo cuyo leitmotiv es la disputa establecida

[20] El original en alemán dice: „Ich habe Schellings Spätphilosophie so gelesen und interpretiert, daß ich mich gegen sie gesperrt habe: letztlich, weil ich das Einvernehmen zwischen Offenbarung und Autonomie nicht begreife.“ 
con la filosofía de la historia. El texto capital de esta lectura es su libro Schwierigkeiten mit der Geschichtsphilosophie, publicado en 1973, y que le sirve como trasfondo para desarrollar su tesis en torno a la filosofía de la historia, a saber: "La filosofía de la historia no es la modernidad, por el contrario, la modernidad se malogra en ella" (Marquard, 2007: 22) y posteriormente matiza esta caracterización mediante la vinculación de la filosofía de la historia con la gnosis: "el neognosticismo de la filosofía de la historia" (Marquard, 1983: 166). ${ }^{21}$ La tesis de Marquard gira en torno al modo en que la filosofía de la historia precisa una filosofía de la coartada, esto es, busca el modo de justificar que el mal en el mundo, si bien es un efecto de la libertad humana, es un problema de los otros, puesto que la filosofía de la historia intenta a quedarse con el título de filosofía perennis, haciendo superfluas o subsidiarias cualquier otro tipo de posturas filosóficas. De este modo, la filosofía de la historia retoma la premisa gnóstica que diferencia entre el creador del mundo, y el redentor del mundo. Así, si los hombres son los creadores de la historia, no todos son sus redentores, sino que solamente algunos, o incluso, ninguno de los que ya ha sido. A esta distinción entre creación y redención subyace, piensa Marquard, una dificultad para decir sí al mundo (Marquard, 1990) que conduce a una actitud de negar el mundo, lo que significa la reivindicación del pensamiento escatológico y apocalíptico. Y es en este punto que la filosofía de la historia traiciona a la modernidad, pues en tanto que la modernidad había sido, precisamente, la neutralización de la escatología bíblica, la filosofía de la historia se presenta como la antimodernidad al apelar de nuevo a la escatología, ahora incluso en el plano de la vida intramundana, en una teología política. ${ }^{22}$ Este caracterización es aplicada por Marquard a la propuesta filosófica de Taubes: "Jacob Taubes ha representado esta tesis: la filosofía central de la modernidad es la filosofía de la historia y

[21] El original en alemán: "den Neognostizismus der etablierten Geschichtsphilosophie“

[22] Este es un punto de constante actualidad en la interpretación del pensamiento de Marquard, máxime cuando renacen los debates en torno a la teología política, o lo que es lo mismo, la búsqueda soteriológica mediante el poder intramundano. Sobre este punto de las vinculaciones entre modernidad y escatología en el pensamiento de Marquard remitimos al lector al libro de Carles Llinàs (Llinàs, 2014) titulado Escatologia i Modernitat. El pensament d' Odo Marquard, en donde el autor desarrolla las discusiones específicas en torno al estatuto de la filosofía de la historia en el pensamiento de Marquard ante las posturas de Blumenberg, Löwith y Taubes. La séptima y la novena conclusión que presenta Carles Llinàs vuelven precisamente sobre este punto, en el que la modernidad, como intento de neutralización de la escatología judeocristiana, se las ve de nuevo con ella en la confrontación entre la apocalíptica filosofía de la historia y la teología política. Así, el autor dice: "Així doncs, el terme «escatologia», en l'ús que en fa Marquard, sembla tenir al capdavall només dues accepcions fonamentals clarament distinguibles: la que correspondria a una intenció de sentit intensiva però metahistòrica (ortodoxia cirstiana patrística i medieval) i la que correspondria a la intenció directa -intrahistòrica- de sentit característica de... la moderna filosofía revolucionària de la història... “ (Llinàs, 2014, pág. 246) 
esta es la continuación de la gnosis mediante el uso de medios modernos" (Marquard, 1983: 160). ${ }^{23}$

El trabajo de Taubes se inclina, por el contrario, a las vinculaciones prácticas del motivo teológico de la redención. Desde la publicación de su disertación Escatología occidental, ya Taubes había mostrado su inclinación hacia el mesianismo de Benjamin, quien también era judío. De este modo, Taubes encontró en el gnosticismo una forma de reivindicación de la apocalíptica como destino del mundo, esto es, como revelación y redención ante el desorden de un mundo que se mueve en diversas direcciones y carece de orientación. Así lo consigna Taubes en su texto Apokalypse und Politik. Ihre Wechsel Wirkung in Übergangs-gesellschaften. Einführende Bemerkunge (Taubes, 2017, págs. 231-236) y en su trabajo sobre Benjamin y Carl Schmit, respectivamente: Walter Benjamin - ein moderner Marcionit? Scholems Benjamin- Interpretation religionsgeschichtlich überprüft (Taubes, 2017: 286-299) y Carl Schmitt - Ein Apokalyptiker der Gegenrevolution (Taubes, 2017: 271-286). De este modo, la figura de Taubes se presenta como la contrapartida de la propuesta de Marquard. Donde este ve problemas con la filosofía de la revelación y el gnosticismo por terminar en una apocalíptica, el primero encuentra ventajas precisamente en los mismos motivos. Una vez con este contexto reconstruido, podemos proceder a lo que hemos denominado como la segunda apelación a Schelling, que si bien no cambia en lo sustancial los argumentos, hay motivos que matizan las posiciones de ambos autores.

\section{La Alabanza del Politeísmo y el descargo DEL MOTIVO DE LA SALVACIÓN: MARQUARD}

La alabanza del politeísmo de Marquard es la consecuencia de la propuesta que el mismo Marquard hace de una historia multiversal. Así, frente a las pretensiones de univocidad y exclusividad de la historia universal, a la corta vida del hombre le conviene una historia multiversal, que consiste propiamente en la posibilidad de:

...no tener solo una única historia o unas pocas historias, sino muchas historias... La historia de las universalizaciones es aquí una de las muchas historias: se puede aprobar la historia universal sólo si ésta está dispuesta a no ser la única historia, sino una historia (y no precisamente la más importante) entre muchas otras historias. (Marquard, 2000b: 87)

[23] El original en alemán dice: „Jacob Taubes hat — zugespitzt formuliert — die These vertreten: die Zentralphilosophie der Neuzeit ist die Geschichtsphilosophie, und diese ist F onsetzung der Gnosis unter Verwendung neuzeitlicher Mittel.“ 
Por ello, la alabanza del politeísmo ilustrado cita es una defensa de la pluralidad de historias, y en consecuencia, una radicalización de la postura de Marquard contra la filosofía de la historia. De este modo, la filosofía de la historia queda calificada como el monomito postmonoteísta (Marquard, 2000a: 111), cuyo lema reza de modo imperativo: "yo soy tu única historia, no tolero que convivas con otras" (Marquard, 2000a: 108). Marquard desarrolla este argumento pasando, nuevamente, por la obra de Schelling, pero ahora haciendo matices importantes en su interpretación.

Inicia reconociendo que la idea de una "nueva mitología", tal y como aparece en el programa más antiguo de un sistema del idealismo alemán procede de la cosecha del propio Schelling, uniéndose con ello a las tesis de Rosenzweig y Tillitete. Y curiosamente, el mismo Schelling no termina consagrándose como el filósofo de la nueva mitología, sino "como el filósofo de la mitología absolutamente antigua" (Marquard, 2000a: 112). Ahora Marquard toma distancia de su postura inicial y acepta que esta lectura no es válida ya en el marco de la filosofía de la identidad; con ello, toma atenta nota de las consideraciones que hiciera en su momento Peter Szondi y diferencia el rol que desempeña la mitología en la filosofía del arte de Schelling, del rol que desempeña en otras etapas de su pensamiento.

Marquard avanza un poco más en su diagnóstico: "Schelling juzgará que esa exigencia de la nueva mitología resulta manifiestamente problemática e incluso sospechosa" (Marquard, 2000a:112-113), ya que la nueva mitología resultó exitosa presentándose como mitología de lo nuevo: "el mito del progreso, de la revolución, de la transformación del mundo, del reino venidero, de la huelga general, de la última batalla y de la última clase" (Marquard, 2000a: 113). Así, la nueva mitología que habría de ofrecer el espacio de un monoteísmo de la razón y politeísmo de la fantasía y el arte, termina en la imposición de un único mito con pretensiones de validez absoluta. Este diagnóstico lo realiza Schelling, según Marquard, y por ello es en Schelling mismo donde empieza el malestar por la nueva mitología:

A mi juicio, las obras tardías de Schelling representan ya una reacción contra este malestar: toman distancia, en sentido literal, frente a la nueva mitología. Por ello la Filosofía de la mitología de Schelling no tiene precisamente a la nueva mitología como objeto de su preocupación, sino a la mitología absolutamente antigua; por ello su Filosofía de la revelación intenta localizar la nueva mitología en su estado más antiguo y tenerla así como posición; pues la revelación cristiana es la nueva mitología más antigua. (Marquard, 2000a: 113).

Marquard marca un viraje en este texto respecto a su contribución hecha en 1968. En primer lugar, desplaza la discusión del ámbito de una filosofía de 
la identidad; y en segundo lugar, incluye la filosofía de la revelación, pero no como la continuación de la filosofía de la mitología, sino como filosofía de la mitología por otros medios. Ante el malestar por una nueva mitología, la antigua mitología, se presenta como la forma más lograda de mitología, y entre ellas, la nueva mitología más antigua es el cristianismo, y es tarea de la filosofía de la revelación tenerla así, esto es, como mitología. Marquard no solamente no cede ante la propuesta hecha por Taubes, sino que incluye la filosofía de la revelación en escena para otorgarle una tarea mitológica. Pese a la arriesgada interpretación que aventura Marquard, él mismo intenta un criterio de corrección ante la erudición de un especialista: "espero que mi interpretación aquí propuesta sea compatible con la de W. Schulz" (Marquard, 2000a, pág. 113) aunque no brinda un mayor desarrollo.

Si revisamos la interpretación ofrecida por Schulz al respecto, podemos validar la tesis de Marquard, en cierta medida. Schulz indica que "lo que en 1796 se llama ,mitología de la razón', significa en 1850 'Poder despotenciado'. Pero en ambos casos se trata de lo mismo: de un cumplimiento completo" (Schulz, 1975: 306). ${ }^{24}$ De este modo, la interpretación que Marquard hace de la filosofía de la revelación, cuyo tema es propiamente la filosofía de la mitología, es propiamente el culmen de la des-potenciación en el desarrollo de la historia; lo que significa, que ninguna revelación puede estar por encima de la última mitología (que en el caso de Schelling es el cristianismo); o lo que es lo mismo, que la revelación es una mitología más y, en consecuencia, no constituye la antítesis de la mitología. De este modo, en la reducción de la revelación a la mitología, la revelación queda articulada en una comprensión intramundana, con lo que la salvación, como tal, no depende de la revelación misma, sino que son apenas comprensiones de las formas de la "mitología de la razón", ya que la revelación al expresar el culmen de la manifestación del absoluto, no puede sustraerse a la despotenciación de la consecución del desarrollo histórico del absoluto mismo. Así, cualquier apelación a la filosofía de la revelación cuyo contenido sea algo diferente a lo contenido en la mitología, por ejemplo, una doctrina de salvación, redunda en una filosofía de la historia y en consecuencia, en la promulgación de un nuevo "monomito postmonoteísta".

\section{Revelación EN LUgar De Politeísmo: Taubes}

La respuesta de Taubes se encuentra en su texto Sobre el auge del politeísmo (Taubes, 2008), quien ha enfatizado su postura en contra de la reducción de la

[24] El original en alemán dice: „Was hier - 1796 - „Mythologie der Vernunft“ heißt, erscheint dort - 1850 - als „ohnmächtige Macht“. Es ist beides dasselbe: vollendete Vollendlichkeit." 
revelación a la mitología; y con ello, contra un renovado auge del politeísmo. ${ }^{25}$ Esta vez Taubes intenta tomarse en serio el dilema que se le presenta a Marquard y parte precisamente de este diagnóstico:

Odo Marquard no lleva adelante una reconstrucción romántica del mito, no se ocupa tampoco del Epotencial de eficiencia del mito" in aesthetics, ni le interesa "la actualidad del mito" como compensación por la "indiferencia del mundo"; su "elogio del politeísmo" se desarrolla cara a cara con la crisis de la historia. (Taubes, 2008: 352)

El diagnóstico de Taubes es justo con las pretensiones de Marquard, y con esta claridad, emprende el camino contrario, pues la historia no se redime de su crisis a través de una apelación al mito, sino mediante un giro radical y contundente sobre el elemento que posibilita la historia misma, a saber, la revelación. Para la construcción de este argumento, apela nuevamente a Schelling, pero decantándose ahora por las juveniles lecciones sobre el método de los estudios académicos, en particular por la octava lección, que tiene por tema la construcción histórica del cristianismo. Taubes retoma la tesis de Schelling, para quien el cristianismo se diferencia del politeísmo por su carácter histórico, pues la realidad se entiende en términos de un "reino moral y el universo en general se ve como historia” (Schelling V, 287). De este modo, solamente mediante la comprensión del cristianismo como revelación puede entenderse la historia como histórica, ya que no se tratan de mitos, relatos y leyendas, sino de la compaginación racional de causas, motivos y fines que orientan el desarrollo del absoluto.

Sobre ello aventura Taubes una ingeniosa tesis: la diferencia entre mito y revelación podría equipararse a la diferencia entre prehistoria e historia, y esta equiparación procede de Schelling, ${ }^{26}$ de tal modo que la distinción operante en

[25] Sobre este auge del politeísmo en el mundo contemporáneo, en el marco específico de los desarrollos y alcances de la filosofía de la historia en el debate en torno a la secularización, remitimos al lector al trabajo de Hauke Ritz, titulado Der Kampf um die Deutung der Neuzeit en especial p. 236-240. Más allá de la referencia, el libro resulta de suma relevancia para este trasfondo ya que el último capítulo está dedicado enteramente al pensamiento de Taubes y a su interpretación de la filosofía de la historia como historia sagrada y revelación. Es inspirador el apartado titulado Offenbarung und Philosophiegeschichte, en el que el autor muestra las tendencias apocalípticas y políticas (revelación y redención) que se ofrecen en el marco de la propuesta de Taubes. Ya que la figura de Schelling no desempeña un papel preponderante en la exposición que hace el autor del pensamiento de Tabes, dejamos esta referencia apenas señalada en una nota.

[26] La cita de Taubes dice lo siguiente: «En sus últimas lecciones, Schelling distingue, con la mejor de las intenciones, la 'filosofía de la mitología' de la 'filosofía de la revelación', dis- 
las ciencias humanas entre la historia y la prehistoria, a partir de la escritura, aplica también en esta distinción: la revelación siempre está escrita; los mitos no. De este modo, el tiempo histórico para Schelling, prosigue Taubes, se diferencia cualitativamente del tiempo prehistórico, y no hay continuidad entre los mismos, sino que "son dos tiempos esencialmente diferentes y separados entre sí, mutuamente excluyentes, pero por eso mismo, fronterizos" (Schelling XI, 231). De este mismo modo, el tiempo del mito y el tiempo de la revelación son diferentes, porque coinciden con el tiempo de la prehistoria y el de la historia, respectivamente. Así, el esfuerzo realizado por la ilustración, y sobre el que insiste Marquard, de reducir la revelación a un mito, constituye la disolución de la historia a favor de la prehistoria: en resumidas cuentas, la alabanza del politeísmo es la claudicación de la historia ante el mito. El elogio del politeísmo dejaría a un lado el problema de la historia, mas sin historia, es imposible el desarrollo de una conciencia moral. (Taubes, 2008: 354) Esta es la dificultad de un elogio del politeísmo.

Las consecuencias de la tesis de Taubes solo admiten el radicalismo de la filosofía de la historia, bien sea en la forma de Schelling bajo la comprensión de la historia como constitución de la persona autónoma en sí misma (Taubes, 2008, pág. 358); o en la forma de Marx, bajo la caracterización científica de las formas históricas (Taubes, 2008, pág. 358). De modo que la operación que llevan a cabo Schelling y Marx en favor de un concepto desmitologizado de historia, y que abren la filosofía al futuro, equivalen a un giro copernicano, con lo que, en opinión de Taubes, "Schelling y Marx llevan adelante la intención de Kant" (Taubes, 2008, pág. 358). La tesis de Taubes resulta diametralmente opuesta a la de Marquard: solo hay historia en la postulación de una filosofía de la historia.

La propuesta de Taubes culmina con una apelación fulminante contra el mito, apelando a Schelling una vez más, al tiempo que invita a Marquard a acceder a las premisas de la filosofía de la revelación:

He recurrido a Schelling porque Marquard también lo convoca como su testigo principal en su "elogio del politeísmo". Seguramente ningún filósofo desde Vico haya descrito el carácter histórico y la función en la formación de los pueblos de manera tan incisiva como el Schelling tardío. Ninguno supo tampoco tan claramente como él que después de Cristo no se puede convocar a los dioses, sólo se puede conjurarlos... La propuesta que le hago a Odo Marquard es, por tanto, avanzar de una filosofía de la mitología a una filosofía de la revelación (obviamente), ilustrada. Si bien de esta manera no sería posible superar las dificultades

tinción que corresponde aproximadamente a la que suele hacerse entre "prehistoria" e "historia".» (Taubes, 2008, pág. 356) 
de la historia y su filosofía, tal vez se podría resolver algunos de sus problemas. (Taubes, 2008: 357)

\section{CONCLUSIONES}

Marquard no respondió directamente a este ensayo de Taubes. Podrían rastrearse respuestas que en cierta medida apuntan a resolver las dificultades que Taubes denuncia, y a su vez, respuestas de vuelta por parte de Taubes; sin embargo, quedan por fuera de este trabajo ya que no incluyen nuevas variaciones sobre las lecturas de Schelling, que fue el marco de nuestro trabajo. ¿Son adecuadas las interpretaciones que formulan Taubes y Marquard de Schelling? No es nuestra labor dirimir la lucha entre Taubes y Marquard a partir de la mejor interpretación de Schelling, ni tampoco nos interesa fungir de misioneros de Schelling para justificar las malas lecturas de ambos filósofos respecto a lo que realmente dijo Schelling; empero, si si trajésemos a colación a los expertos en el tema como lo son Markus Gabriel (Gabriel, 2006), John Willson (Wilson, 1993) Edward Beach (Beach, 1988), las interpretaciones de Marquard y de Taubes no resistirían una crítica filosófica por parte de un comentarista experto en los textos de Schelling, y no obstante, la valía del debate no reside en qué tan acertadas son o no las exégesis filosóficas de cada uno de los intérpretes, sino en lo que un filósofo es capaz de pensar a partir de lo que otros han pensado. La querella en torno al politeísmo es un ejemplo de esta situación y sus frutos no dependen de la exactitud con que ambos autores leen a Schelling, sino lo lejos que son capaces de llevar sus propios pensamientos a partir de la reconstrucción de la filosofía de Schelling. Hay algo conveniente en las malas lecturas, y es que evitan el dogmatismo y el cierre de horizontes a una única perspectiva. Quizás este hecho sea un peso más en la balanza a favor de Marquard por encima de la opinión de Taubes.

Es por ello que en este debate me inclino por la posición de Marquard, no tanto por la conformidad con sus argumentos a favor de una Elogio del politeísmo en tanto politeísmo ilustrado, pues esto sería tema de otro trabajo, sino porque la lectura que hace de Schelling me resulta filosóficamente más sugerente que la de Taubes. Lo que encuentro sugerente es el modo de abordar la filosofía de un autor a contrapelo, ya que intenta lo arriesgado: leer algún elemento de la filosofía de Schelling como una consigna heterónoma. Y este riesgo que toma Marquard en su lectura, corresponde con la multiversalidad y con el politeísmo ilustrado que profesa. En tanto que la consigna de Taubes se expresa en la premisa: "Del culto a la cultura" (que es el título de su libro), la propuesta de Marquard es "Del culto a la biblioteca" (Marquard, 1983); esta variación no es meramente retórica, sino que define un programa filosófico. Lo que fue motivo de culto (revelación) no ha de valer como cultura dominante, sino como pluralidad en la formación (mito). 
En definitiva, la tesis de Marquard es que Schelling no presenta una crítica de la mitología, sino que hay precisamente una alabanza de ella, más no una alabanza que desea su gloria, sino una alabanza que celebra su despedida. En consecuencia, si bien la filosofía de la mitología conlleva un matiz de heteronomía, y en el marco de la consecución de una historia autónoma no tendría cabida el mito; la mitología ofrece, compensatoriamente, formas de descarga ante las contingencias heterónomas que constituirían el escenario en que el hombre finito elabora, autónomamente, la historia. Esta tesis queda sostenida a partir de dos grandes argumentos:

El primero refiere la disputa entre Taubes y Marquard a propósito del rol de la filosofía de la revelación y de la mitología en Schelling. Mientras que, para el primero, la filosofía de la mitología de Schelling termina en la defensa de una filosofía de la revelación; para el segundo, la filosofía de la revelación habría de ser leída como la filosofía de la nueva mitología más antigua. Con ello, se abre el debate entre la reivindicación de una filosofía ilustrada de la revelación, propuesta por Taubes, y la propuesta de un politeísmo ilustrado, sostenido por Marquard. En este sentido, el argumento se construye en virtud de cómo la revelación, en tanto factor extramundano y propio de la filosofía de la revelación, constituiría precisamente el elemento heterónomo en la historia; razón por la cual es inviable el camino que pretende franquear el paso entre una historia autónoma y una filosofía de la revelación. En breve: la revelación no garantiza la autonomía, sino la obediencia.

El segundo argumento refiere a la configuración de la historia como producto de la autonomía humana, y en consecuencia, a la contraposición entre historia y mito señalada por Taubes. Siendo el mito, en términos de Marquard, una defensa de lo contingente, su inclusión en la historia defiende la autonomía curándola del exceso propio de autonomía: una visión totalitariamente autónoma de la historia. De este modo, la autonomía sigue comprendiéndose como una autonomía situada entre las contingencias, que constituyen sus condiciones de posibilidad. Ello implica la transformación de una filosofía de la revelación en una filosofía de la mitología.

La conclusión que se siguen de estas consideraciones es que la inclusión de la mitología en el marco de una historia autónoma hecha por parte del hombre, constituye propiamente la despedida (wegloben)de la filosofía de la revelación como monomito, a la vez que es la despedida (wegloben) de la filosofía de la mitología como alabanza del mito con lo que queda abierta la tarea hermenéutica de forjar orientaciones para la lectura del mito en el ámbito de una discusión sobre la filosofía de la historia. Así, la posibilidad de abordar filosóficamente la historia más allá de su caracterización como una y única historia, propia de un monomito, significa también la posibilidad de abordar la historia más acá de cualquier intención de salvación en su desarrollo. La historia es llevada por 
seres humanos, quienes en su realización, vuelven sobre sus mitos para descargarse de los pesos de los males que implican sus actos, pero de los que se alejan para desarrollar su autonomía en caminos diversos que no están estipulados por ningún criterio de salvación impuesto en una revelación. De este modo, las malas lecturas que Taubes y Marquard pudieron haber hecho de Schelling, constituyen excelentes aportes para el debate contemporáneo en torno al estatuto de la filosofía de la historia y su rol en el mundo contemporáneo.

\section{TRABAJOS CITADOS}

BEACH, E. A. (1988). Schelling's Philosophy of Mythology: A Critical Analysis. Stanford : Stanford University.

GABriel, M. (2006). Der Mensch im Mythos: Untersuchungen über Ontotheologie, Anthropologie und Selbstbewusstseinsgeschichte in Schellings Philosophie der Mythologie. Walter de Gruyter.

LlinÀs, C. (2014). Escatologia i modernitat. El pensament d' Odo Marquard. Barcelona: Cruïlla.

Macho, T. (2001). Der intellektuelle Bruch zwischen Gershom Scholem und Jacob Taubes. Zur Frage nach dem Preis des MEssianismus. En R. Faber, E. GoodmanThau, \& T. Macho, Abendländische Eschatologie ad Jacob Taubes (págs. 531-545). Würzburg: Könighausen \& Neumann.

Marquard, O. (1971). Zur Funktion Mythologiephilosophie bei Schelling. En M. Fuhrmann, Terror und Spiel: Probleme der Mythenrezeption. (págs. 257-263). München: Wilhelm Fink Verlag.

MARQuARD, O. (1981). Die Entäuchsung der emanzipatorischen Naherwartung. Einige Bemerkungen zum modernen Prozess der Entübelung der übel und seiner Krise (mit Rücksicht auf Schelling). En L. Hasler, Schelling. Seine Bedeutung für eine Philosophie der Natur un der Geschichte (págs. 205-215). Zürich: Problemata frommann-holzboog.

Marquard, O. (1983a). Aufgeklärter Polytheismus - auch eine politische Theologie? En J. Taubes, Religionstheorie und politische Teologie. Band 1 Die Fürst dieser Welt Carl Schmitt und die Folgen (págs. 77-84). Wilhelm Fink Verlag.

Marquard, O. (1983b). Theodizee, Geschichtsphilosophie, Gnosis. En N. Bolz, Spiegel und Gleichnis. Festschrift für Jacob Taubes (págs. 160-167). Würzburg: Königshausen + Neumann.

Marquard, O. (1990). Schwierigkeiten beim Ja-sagen. En W. Oelmüler, Theodizee, Gott vor Gerricht? (págs. 87-102). München: Wilhelm Fink Verlang.

Marquard, O. (1995). Grund und Existenz in Gott (350-364). En O. Höffe, \& A. Pieper, F.W.J. Schelling Über das Wesen der menschlischen Freiheit. (págs. 55-59). Berlin: Pieper.

Marquard, O. (2000a). Adiós a los principios. Valencia: Institució Alfons el Magnànim.

Marquard, O. (2000b). Apología de lo contingente. Valencia: Institució Alfons el Magnànim. 
Marquard, O. (2007). Dificultades con la filosofía de la historia. Valencia: Pre-Textos. Marquard, O. (2007). Dificultades con la filosofía de la historia. Valencia: Pre-Textos. Ritz, H. (2014). Der Kampf um die Deutung der Neuzeit. Die geschichtsphilosophische Diskussion in Deutschland vom Ersten Weltkrieg bis zum Mauerfall. Wilhelm Fink Verlag.

Ritz, H. (2015). Der Kampf um die Deutung der Neuzeit. Die geschichtsphilosophische Diskussion in Deutschland vom Ersten Weltkrieg bis zum Maerfall. München: Wilhelm Fink.

Schulz, W. (1975). Die Vollendung des Deutschen Idealismus in der Spätphilosophie Schellings. Stuttgart: Neske.

Szondi, P. (1971). Mythos und Autonomie. En M. Fuhrmann, Terror und Spiel: Probleme der Mythenrezeption (págs. 639-652). München: Wilhelm Fink Verlag.

Taubes, J. (1987). Interview 1986. En F. Rötzer, Denken, das an der Zeit ist (pág. 316). Frankfurt a. M. : Suhrkamp .

TAubes, J. (2008). Del culto a la cultura: Elementos para una crítica de la razón histórica. Buenos Aires: Katz.

TAubes, J. (2017). Apokalypse und Politik. Wilhelm Fink.

Wilson, J. (1993). Schellings Mythologie. Zur Auslegung der Philosophie der Mythologie und der Offenbarung. Stuttgart: frommann-holzboog. 